Supporting Information

\title{
Dual-surface Mechanism of Oxidant-free Pyrrole Polymerization in 2D Titanium Carbide (MXene) Interlayer Nanospace
}

Erol Yildirim, Shermin S. Goh, He-Kuan Luo, Hongmei Jin, * Gang Wu, Teck Leong Tan, Zicong Marvin Wong, Jianwei Xu, and Shuo-Wang Yang* 
$\mathrm{Ab}$ initio MD simulations were performed for 6 ps with 1 fs steps at NVT ensemble with NHL thermostat at $298 \mathrm{~K}$ using PW91 exchange-correlation functional with semiempirical van der Waals (vdW) dispersion correction based on Ortmann-Bechstedt-Schmidt (OBS) scheme and ultrasoft pseudopotentials to confirm stability of geometry optimized $-\mathrm{OH},-\mathrm{O}$, and $-\mathrm{F}$ terminated surfaces. Last 2 ps of the simulations were analyzed for $\mathrm{O}-\mathrm{H}$ bonds, three $\mathrm{C}-\mathrm{O}$ bonds in -O terminated cell and three C-F bonds in -F terminated cell. Simulations and bonds length analysis show that there is not any bond dissociations and formations that confirm the stability of the surface terminations in $\mathrm{Ti}_{3} \mathrm{C}_{2}$ type MXenes.

\section{a}
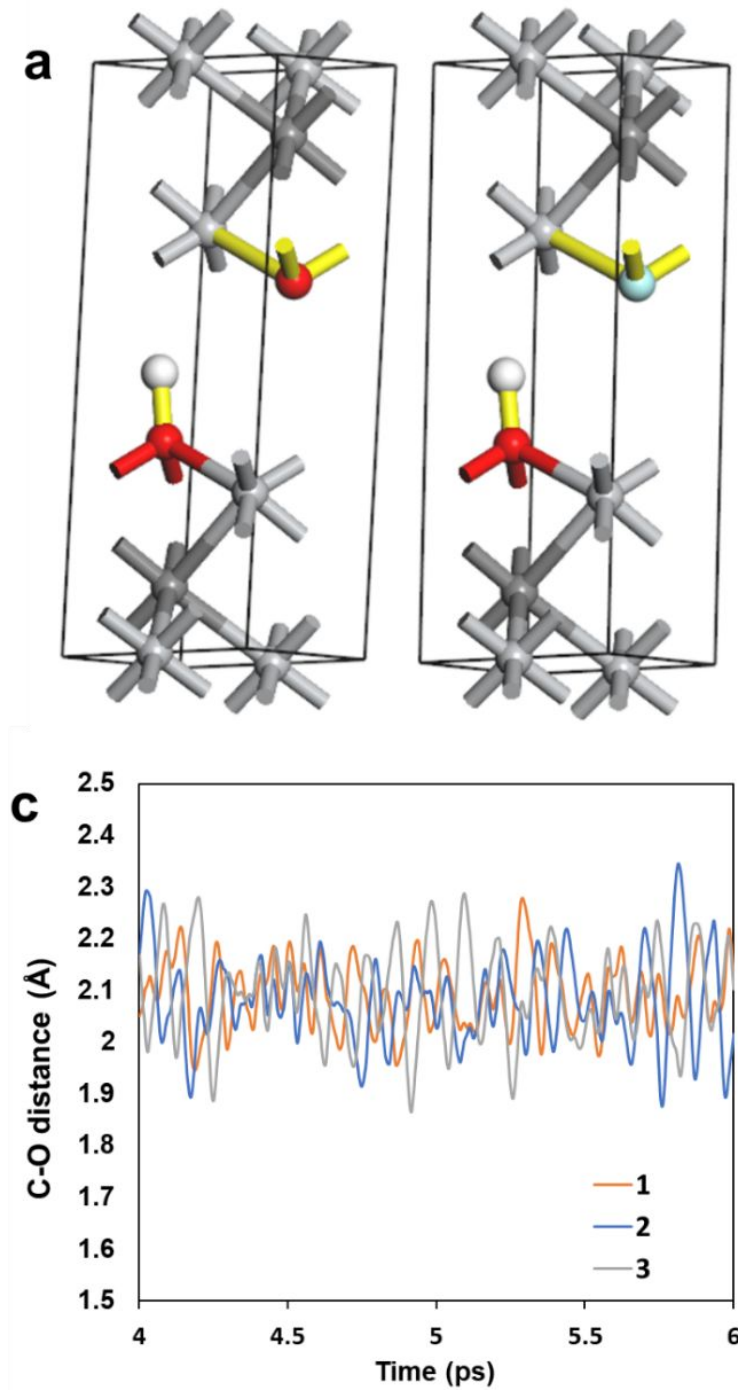
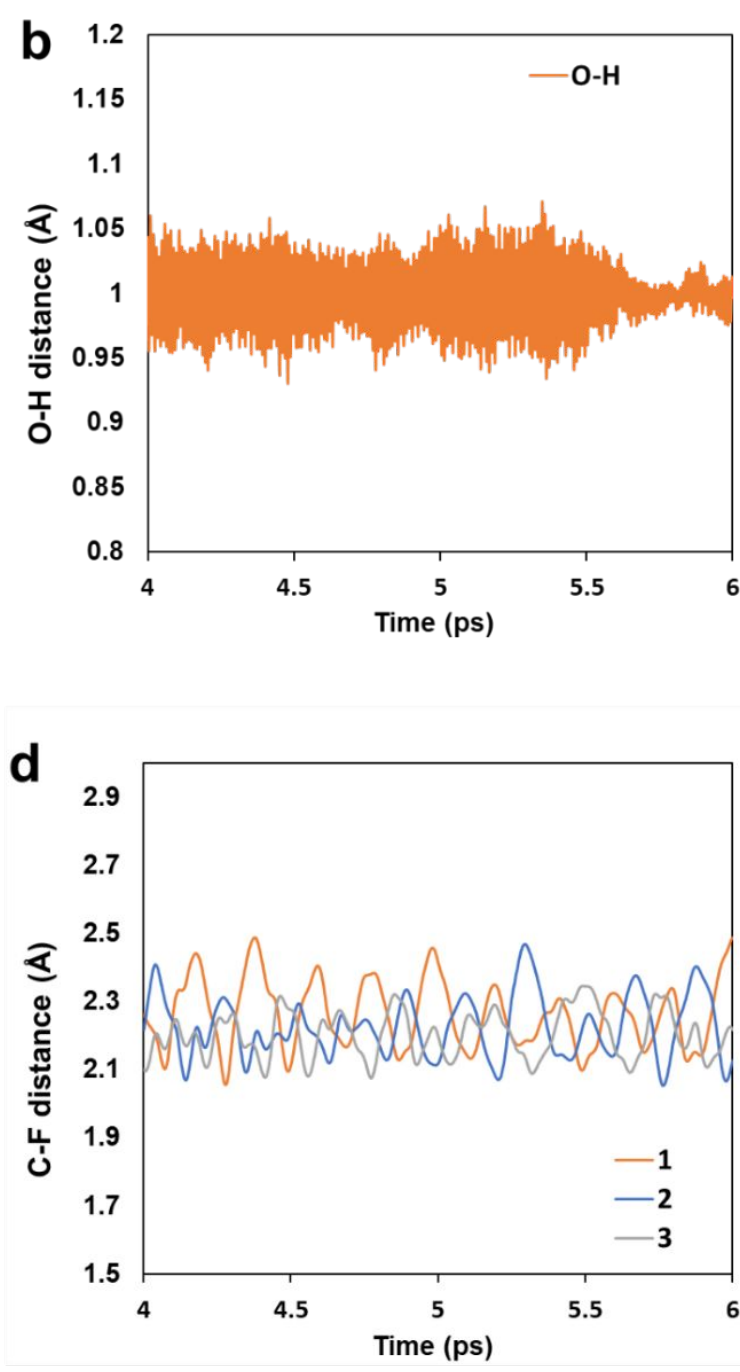

Figure S1. a) $-\mathrm{O}$, and $-\mathrm{F}$ terminated $\mathrm{Ti}_{3} \mathrm{C}_{2}$ surfaces $\left(\mathrm{Ti}_{3} \mathrm{C}_{2} \mathrm{O}(\mathrm{OH})\right.$ and $\left.\mathrm{Ti}_{3} \mathrm{C}_{2} \mathrm{~F}(\mathrm{OH})\right)$ used in ab initio MD simulations. Bonds which are analyzed for the last 2 ps were shown in yellow color. b) Bond length evolution of $\mathrm{O}-\mathrm{H}$ bonds in $-\mathrm{O}$ terminated surface, c) Bond length evolution of $\mathrm{C}-\mathrm{O}$ bonds in $-\mathrm{O}$ terminated surface, d) Bond length evolution of $\mathrm{C}-\mathrm{F}$ bonds in $-\mathrm{F}$ terminated surface. 

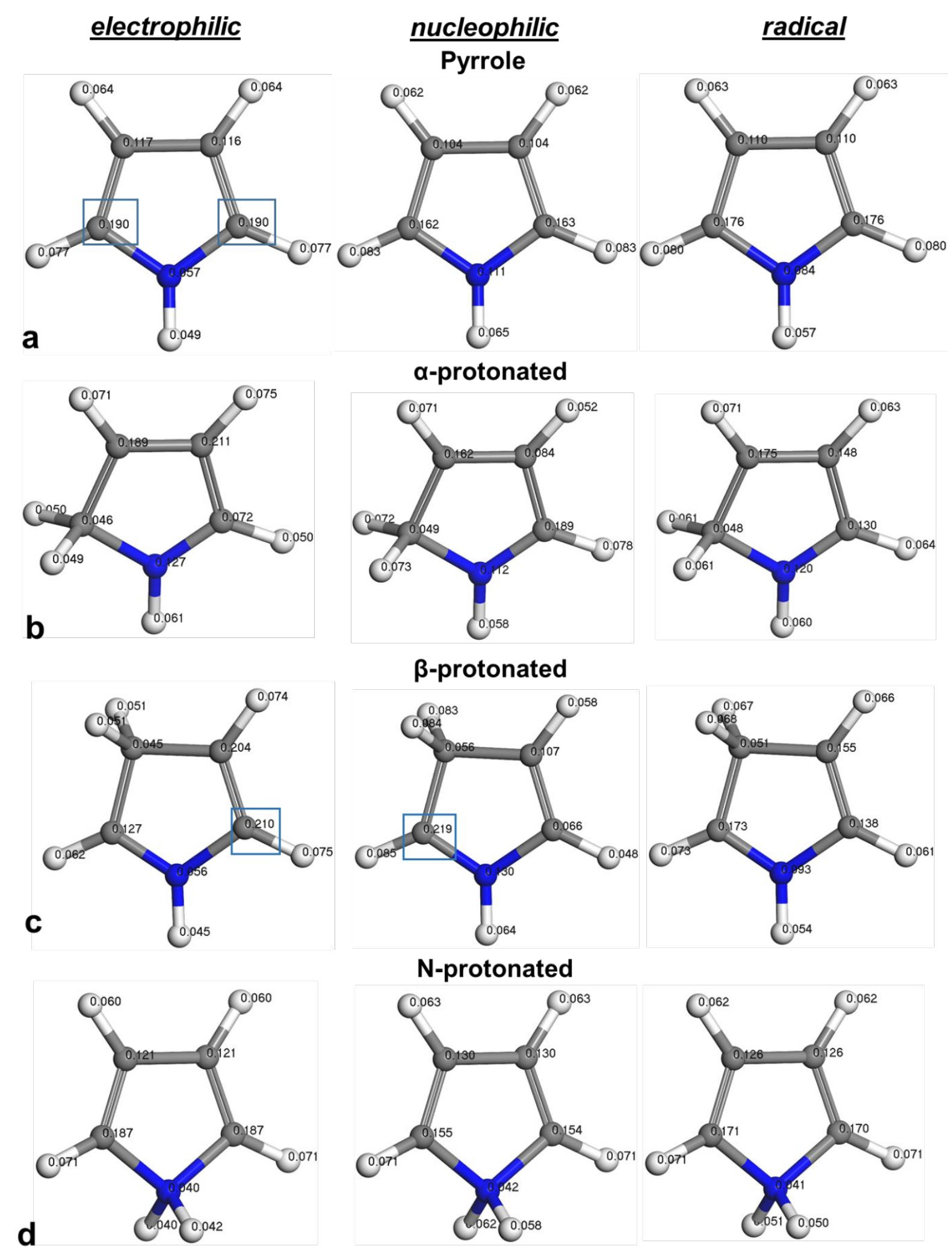

Figure S2a. Fukui electrophilic, nucleophilic and radical reactivity indices for a) pyrrole, b) $\alpha$ protonated pyrrole c) $\beta$-protonated pyrrole d) N-protonated pyrrole calculated by Hirshfeld atomic charges. (carbon: grey; hydrogen: white; nitrogen: blue) 


\section{Mulliken Charge Method}

electrophilic

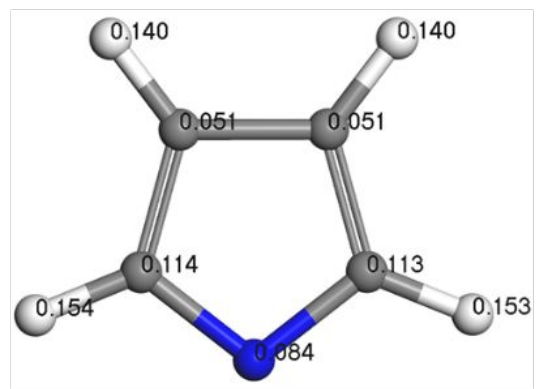

electrophilic

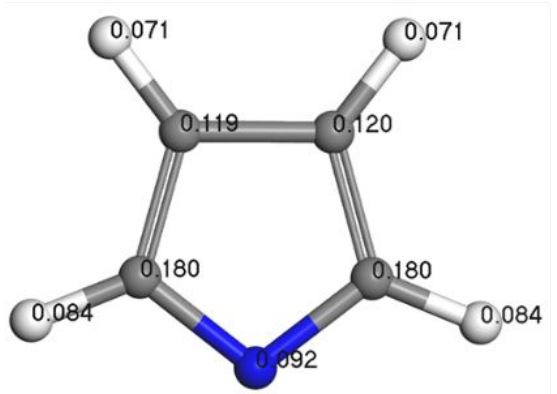

nucleophilic

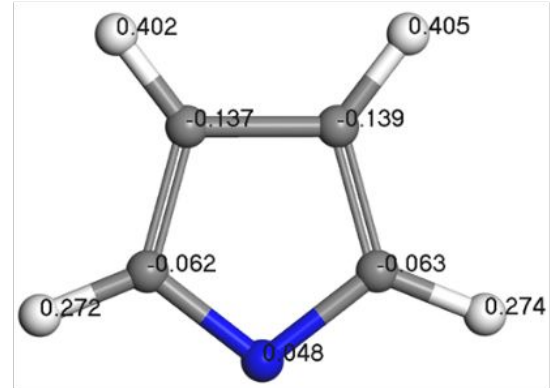

Hirshfeld Charge Method

nucleophilic

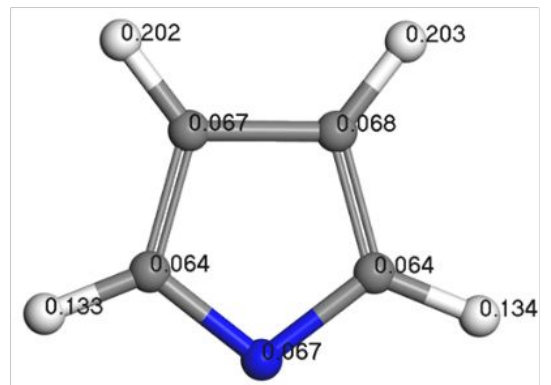

radical

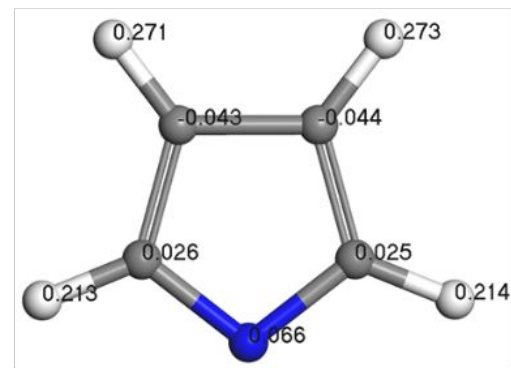

radical

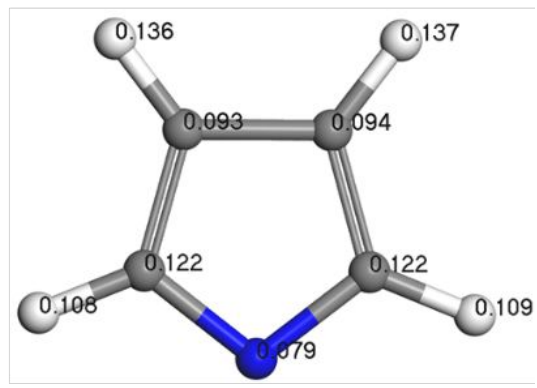

Figure S2b. Reactivity indices for -NH deprotonated pyrrole calculated by B3LYP functional based on two different atomic charge calculation method. 
Table S1a. Fukui electrophilic, nucleophilic, and radical reactivity indices for pyrrole, $\alpha$ protonated pyrrole, $\beta$-protonated pyrrole calculated by using ESP charges.

\begin{tabular}{|c|c|c|c|c|c|c|c|c|c|c|}
\hline \multirow{2}{*}{$\begin{array}{c}\text { Method } \\
\text { Atom No. } \\
\text { M06-2X }\end{array}$} & \multirow[b]{2}{*}{$\begin{array}{l}\text { Atom } \\
\text { Type }\end{array}$} & \multicolumn{3}{|c|}{ NEUTRAL } & \multicolumn{3}{|c|}{ ALPHA } & \multicolumn{3}{|c|}{ BETA } \\
\hline & & $\mathrm{F}_{+}$ & F. & $F_{R}$ & $\mathrm{~F}_{+}$ & F. & $F_{R}$ & $\mathrm{~F}_{+}$ & $F_{\text {. }}$ & $F_{R}$ \\
\hline 1 & $N$ & -0.31 & -0.16 & -0.24 & 0.01 & 0.21 & 0.11 & 0.21 & -0.08 & 0.06 \\
\hline 2 & $\mathrm{Ca}$ & -0.36 & 0.4 & 0.02 & -0.22 & -0.16 & -0.19 & -0.01 & 0.35 & 0.17 \\
\hline 3 & $C \beta$ & -0.01 & 0.03 & 0.01 & 0.16 & 0.28 & 0.22 & 0.16 & 0.39 & 0.28 \\
\hline 4 & $C \beta$ & -0.01 & 0.03 & 0.01 & 0.05 & 0.43 & 0.24 & -0.34 & -0.3 & -0.32 \\
\hline 5 & $\mathrm{Ca}$ & -0.36 & 0.4 & 0.02 & 0.37 & -0.1 & 0.13 & 0.33 & 0.24 & 0.28 \\
\hline \multicolumn{11}{|l|}{ B3LYP } \\
\hline 1 & $\mathrm{~N}$ & -0.39 & -0.14 & -0.26 & 0.04 & 0.25 & 0.14 & 0.21 & -0.05 & 0.08 \\
\hline 2 & $\mathrm{Ca}$ & -0.32 & 0.37 & 0.02 & -0.25 & -0.2 & -0.23 & -0.01 & 0.32 & 0.15 \\
\hline 3 & $C \beta$ & -0.03 & 0.04 & 0 & 0.17 & 0.28 & 0.23 & 0.18 & 0.37 & 0.27 \\
\hline 4 & $C \beta$ & -0.03 & 0.04 & 0 & 0.06 & 0.37 & 0.22 & -0.36 & -0.29 & -0.33 \\
\hline 5 & $\mathrm{Ca}$ & -0.32 & 0.37 & 0.02 & 0.33 & -0.08 & 0.12 & 0.31 & 0.25 & 0.28 \\
\hline \multicolumn{11}{|l|}{ MP2 } \\
\hline 1 & $N$ & 0.17 & -0.23 & -0.03 & -0.01 & 0.33 & 0.16 & 0.21 & -0.13 & 0.04 \\
\hline 2 & $\mathrm{Ca}$ & 0.06 & 0.46 & 0.26 & -0.16 & -0.21 & -0.19 & -0.06 & 0.42 & 0.18 \\
\hline 3 & $C \beta$ & 0.14 & 0.03 & 0.08 & 0.13 & 0.33 & 0.23 & 0.13 & 0.44 & 0.28 \\
\hline 4 & $C \beta$ & 0.14 & 0.03 & 0.08 & -0.02 & 0.43 & 0.21 & -0.28 & -0.33 & -0.3 \\
\hline 5 & $\mathrm{Ca}$ & 0.06 & 0.46 & 0.26 & 0.47 & -0.2 & 0.14 & 0.38 & 0.23 & 0.31 \\
\hline
\end{tabular}

Table S1b. Fukui electrophilic, nucleophilic, and radical reactivity indices for pyrrole, $\alpha-$ protonated pyrrole, $\beta$-protonated pyrrole calculated by using NBO charges.

\begin{tabular}{|c|c|c|c|c|c|c|c|c|c|c|}
\hline \multicolumn{2}{|l|}{$\begin{array}{l}\text { Method } \\
\text { Atom No. }\end{array}$} & \multicolumn{3}{|c|}{ NEUTRAL } & \multicolumn{3}{|c|}{ ALPHA } & \multicolumn{3}{|c|}{ BETA } \\
\hline M06-2X & $\begin{array}{l}\text { Atom } \\
\text { Type }\end{array}$ & $\mathrm{F}_{+}$ & $F_{\text {. }}$ & $F_{R}$ & $\mathrm{~F}_{+}$ & F. & $F_{R}$ & $\mathrm{~F}_{+}$ & $F_{\text {. }}$ & $\mathrm{F}_{\mathrm{R}}$ \\
\hline 1 & $\mathrm{~N}$ & 0.05 & -0.04 & 0.00 & 0.13 & 0.17 & 0.15 & 0.13 & -0.04 & 0.05 \\
\hline 2 & $\mathrm{Ca}$ & 0.02 & 0.30 & 0.16 & -0.06 & -0.06 & -0.06 & 0.00 & 0.31 & 0.16 \\
\hline 3 & $C \beta$ & 0.02 & 0.10 & 0.06 & 0.25 & 0.29 & 0.27 & 0.15 & 0.33 & 0.24 \\
\hline 4 & $C \beta$ & 0.02 & 0.10 & 0.06 & 0.00 & 0.36 & 0.18 & -0.07 & -0.07 & -0.07 \\
\hline 5 & $\mathrm{Ca}$ & 0.02 & 0.30 & 0.16 & 0.27 & -0.05 & 0.11 & 0.37 & 0.16 & 0.26 \\
\hline \multicolumn{11}{|l|}{ B3LYP } \\
\hline 1 & $\mathrm{~N}$ & 0.04 & -0.02 & 0.01 & 0.13 & 0.19 & 0.16 & 0.12 & -0.02 & 0.05 \\
\hline 2 & $\mathrm{Ca}$ & 0.02 & 0.29 & 0.15 & -0.06 & -0.06 & -0.06 & 0.01 & 0.29 & 0.15 \\
\hline 3 & $C \beta$ & 0.02 & 0.11 & 0.06 & 0.24 & 0.27 & 0.26 & 0.15 & 0.31 & 0.23 \\
\hline 4 & $C \beta$ & 0.02 & 0.11 & 0.06 & 0.02 & 0.32 & 0.17 & -0.07 & -0.06 & -0.06 \\
\hline 5 & $\mathrm{Ca}$ & 0.02 & 0.29 & 0.15 & 0.26 & -0.03 & 0.11 & 0.34 & 0.16 & 0.25 \\
\hline \multicolumn{11}{|l|}{ MP2 } \\
\hline 1 & $\mathrm{~N}$ & 0.08 & -0.03 & 0.03 & 0.13 & 0.28 & 0.20 & 0.14 & -0.05 & 0.05 \\
\hline 2 & $\mathrm{Ca}$ & 0.25 & 0.29 & 0.27 & -0.07 & -0.07 & -0.07 & -0.05 & 0.34 & 0.15 \\
\hline 3 & $C \beta$ & 0.08 & 0.10 & 0.09 & 0.24 & 0.29 & 0.26 & 0.13 & 0.34 & 0.24 \\
\hline 4 & $C \beta$ & 0.08 & 0.10 & 0.09 & -0.07 & 0.36 & 0.15 & -0.09 & -0.07 & -0.08 \\
\hline 5 & $\mathrm{Ca}$ & 0.25 & 0.29 & 0.27 & 0.35 & -0.15 & 0.10 & 0.42 & 0.13 & 0.28 \\
\hline
\end{tabular}


Stability of protonated pyrrole

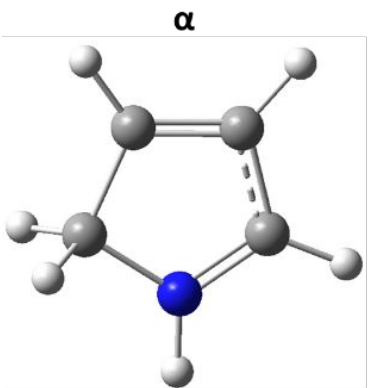

$-5727.681 \mathrm{eV}$

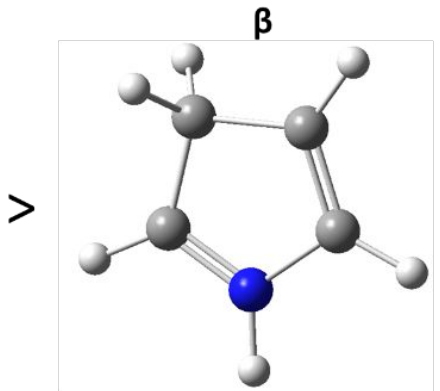

$-5727.469 \mathrm{eV}$

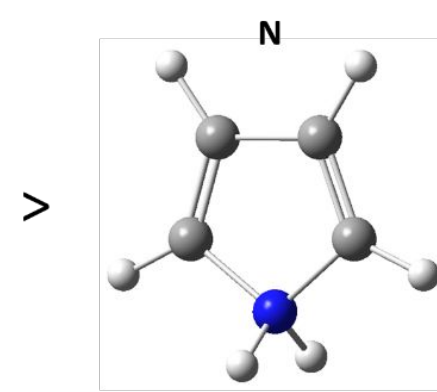

$-5726.882 \mathrm{eV}$

$\mathbf{a}$

Stability of diprotonated pyrrole

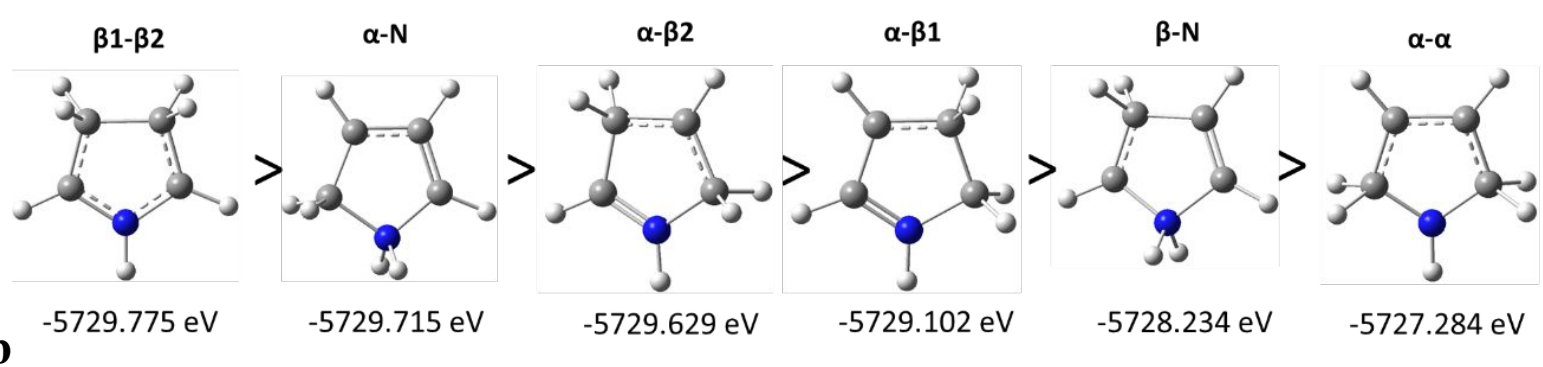

Stability of diprotonated pyrrole ( $N$-deprotonated)

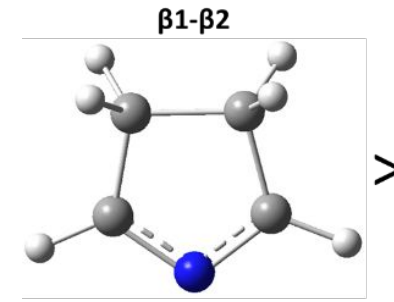

c

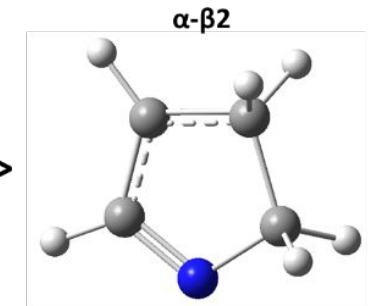

$-5725.316 \mathrm{eV}$

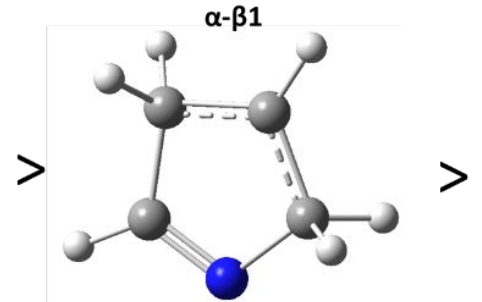

$-5725.062 \mathrm{eV}$

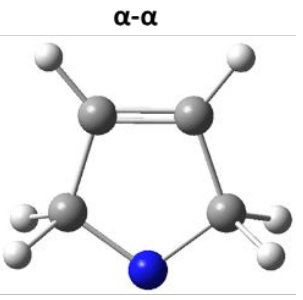

$-5723.997 \mathrm{eV}$

Figure S3. Geometry optimized electronic energy at M06-2X/6-311++g(3df,3pd) level for a) protonated pyrroles, $\mathrm{b}$ ) diprotonated pyrroles, and c) diprotonated pyrroles that are deprotonated at $\mathrm{N}$-atoms. 
Table S2. Reactivity of $\beta$-protonated pyrrole for second protonation determined based on the ESP atomic charges at M06-2X/6-311++g(3df,3pd) level a) without N-deprotonation and b) after N-deprotonation.

a)

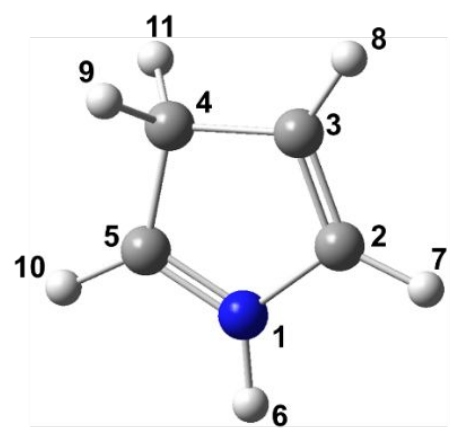

\begin{tabular}{|c|c|c|c|c|}
\hline $\begin{array}{c}\text { Atom } \\
\text { No. }\end{array}$ & $\begin{array}{c}\text { Atom } \\
\text { Type }\end{array}$ & f(nuc) & f(elec) & f(radical) \\
\hline 1 & N & 0.206 & -0.084 & 0.061 \\
\hline 2 & C & -0.012 & 0.351 & 0.170 \\
\hline 3 & C & 0.159 & $\mathbf{0 . 3 9 1}$ & 0.275 \\
\hline 4 & C & -0.335 & -0.296 & -0.316 \\
\hline 5 & C & 0.326 & 0.243 & 0.284 \\
\hline 6 & $H$ & 0.037 & 0.061 & 0.049 \\
\hline 7 & H & 0.075 & 0.014 & 0.045 \\
\hline 8 & H & 0.080 & 0.012 & 0.046 \\
\hline 9 & H & 0.194 & 0.125 & 0.159 \\
\hline 10 & H & 0.075 & 0.059 & 0.067 \\
\hline 11 & H & 0.194 & 0.125 & 0.159 \\
\hline
\end{tabular}

b)

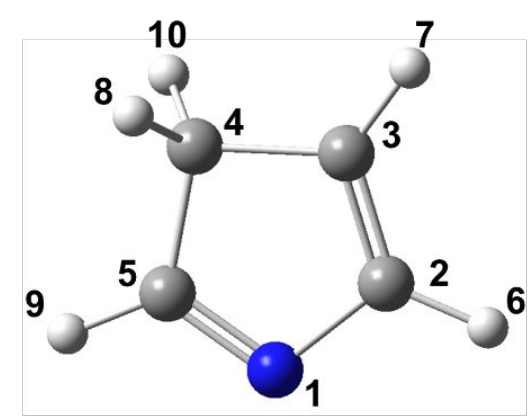

* Highest electrophilic attack site is on atom 3 for both cases which means $\beta 1 \beta 2$ diprotonated pyrrole is preferred. 


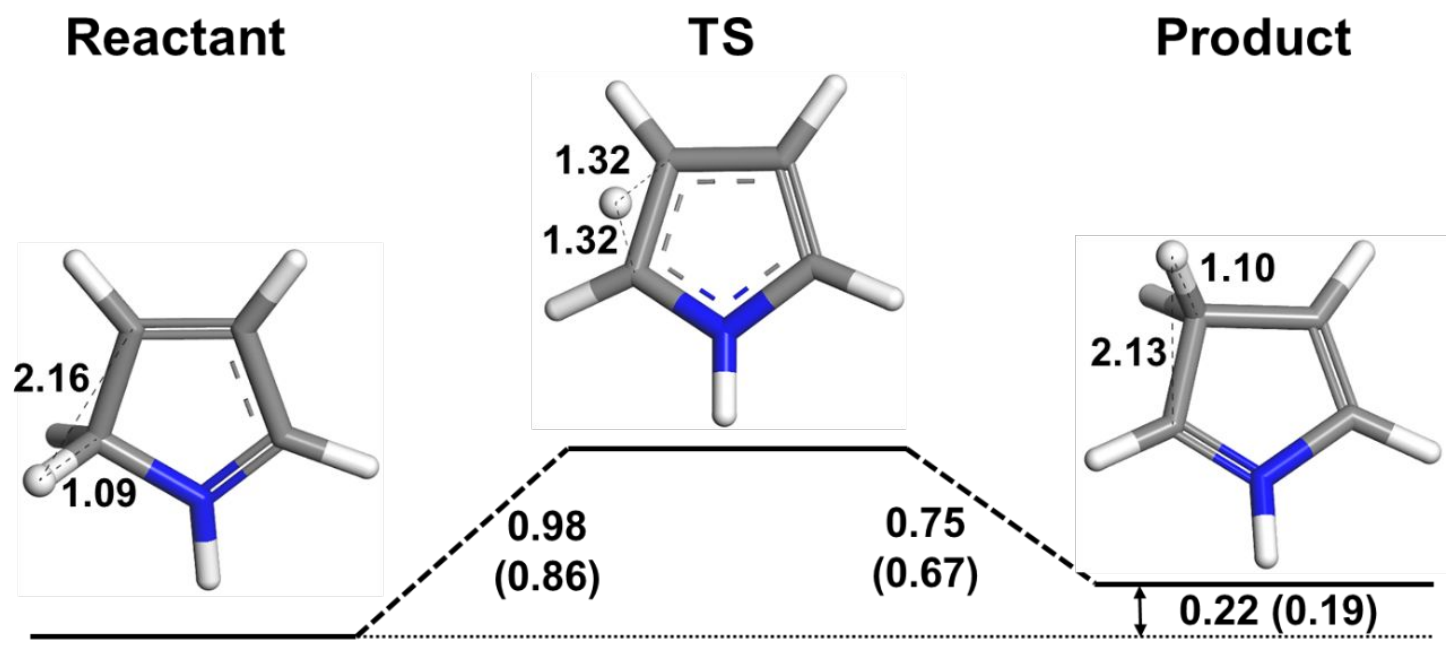

Figure S4. Stability of $\alpha$-protonated pyrrole compared to $\beta$-protonated pyrrole and reaction mechanism for the proton transfer by using B3LYP/6-311++g(3df,3pd) calculations. Results calculated by using M06-2X functional are given in the paranthesis. 


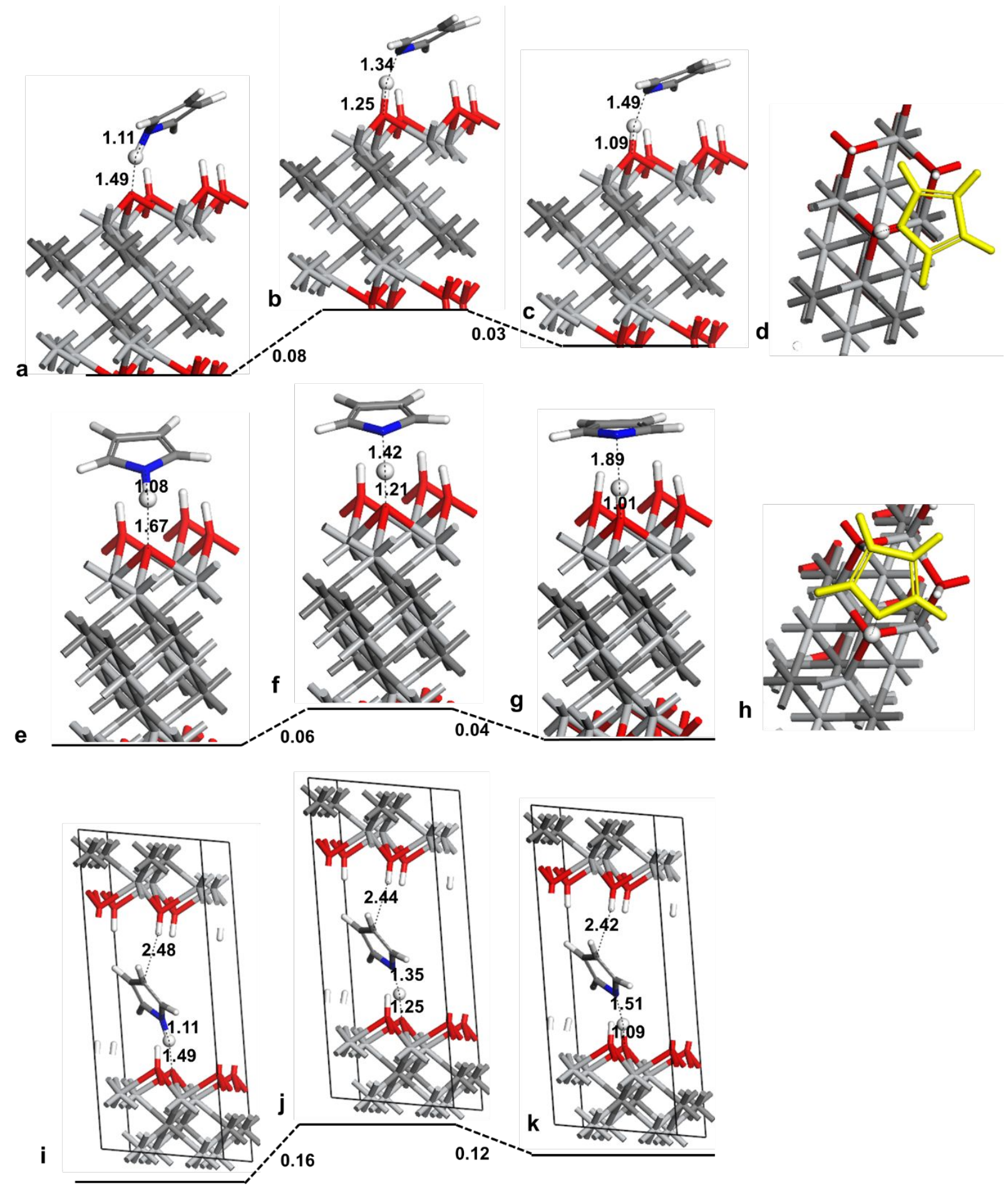

Figure S5. Reactant, transition-state, and product for the proton transfer from -NH group of pyrrole monomer to MXene surface for a-c) conformation 1, (d) top view of conformation1); e-g) conformation 2, (h) top view of conformation2); i-k) conformation 3 (perpendicular pyrrole in the interlayer with $15.6 \AA$ basal spacing). 


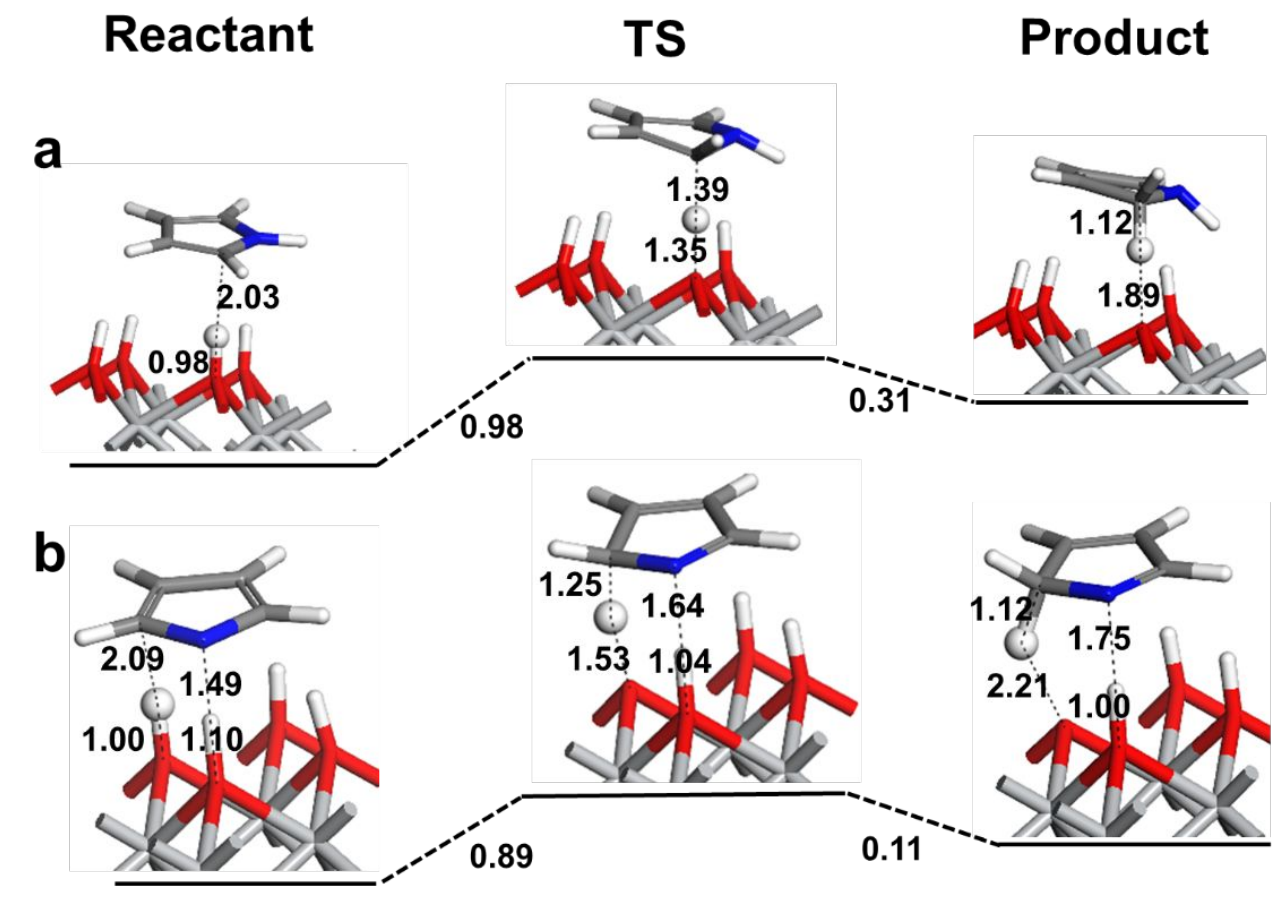

Figure S6. The activation of monomers by protonation reactions: a) $\alpha$-protonation of pristine pyrrole on $-\mathrm{OH}$ terminated MXene surface and $b$ ) $\alpha$-protonation of $\mathrm{N}$-deprotonated pyrrole on -O terminated MXene surface. 


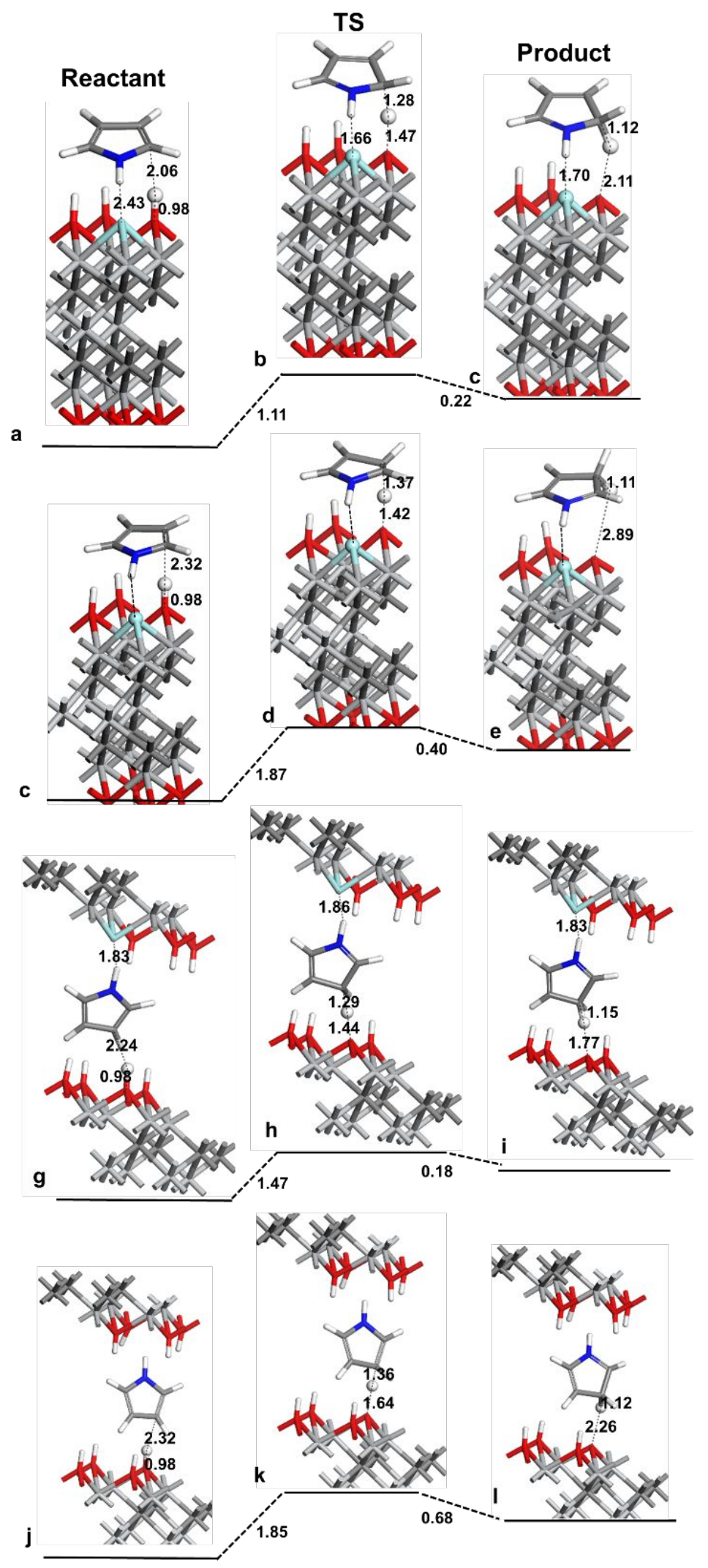

Figure S7. Reactant, transition-state, and product on $-\mathrm{F}$ terminated surface for a-c) $\alpha$ protonation of pyrrole; d-f) $\beta$-protonation of pyrrole; g-i) $\beta$-protonation of pyrrole at the interlayer for perpendicular conformation; and $\mathrm{j}-1) \beta$-protonation of pyrrole for fully hydroxyl terminated surface at the interlayer for perpendicular conformation. 
TS
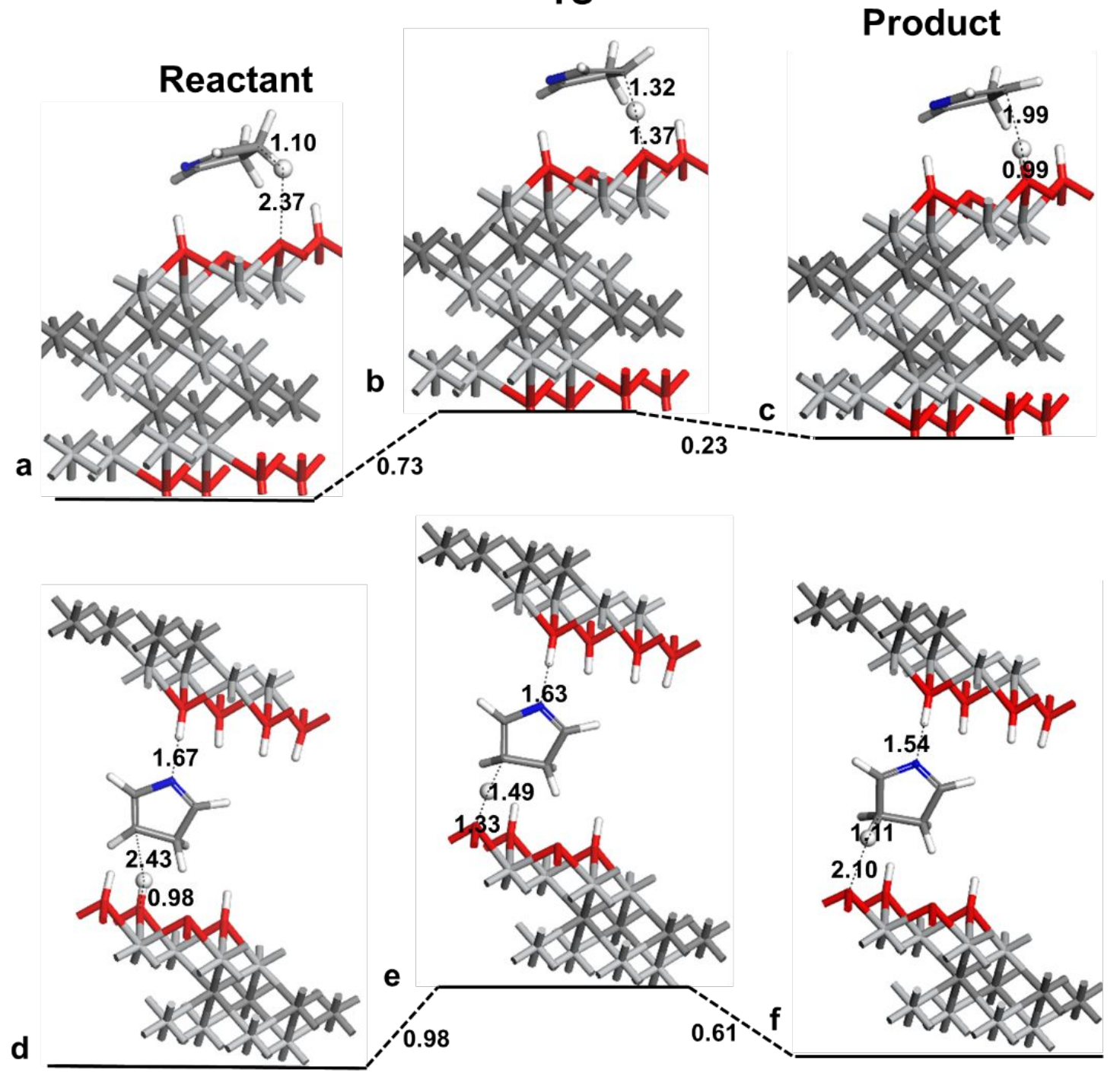

Figure S8. Second proton transfer to the $\beta 2$-carbon of $\beta 1$-protonated pyrrole with a-c) planarand d-f) perpendicular-orientation at the MXene interlayer. 


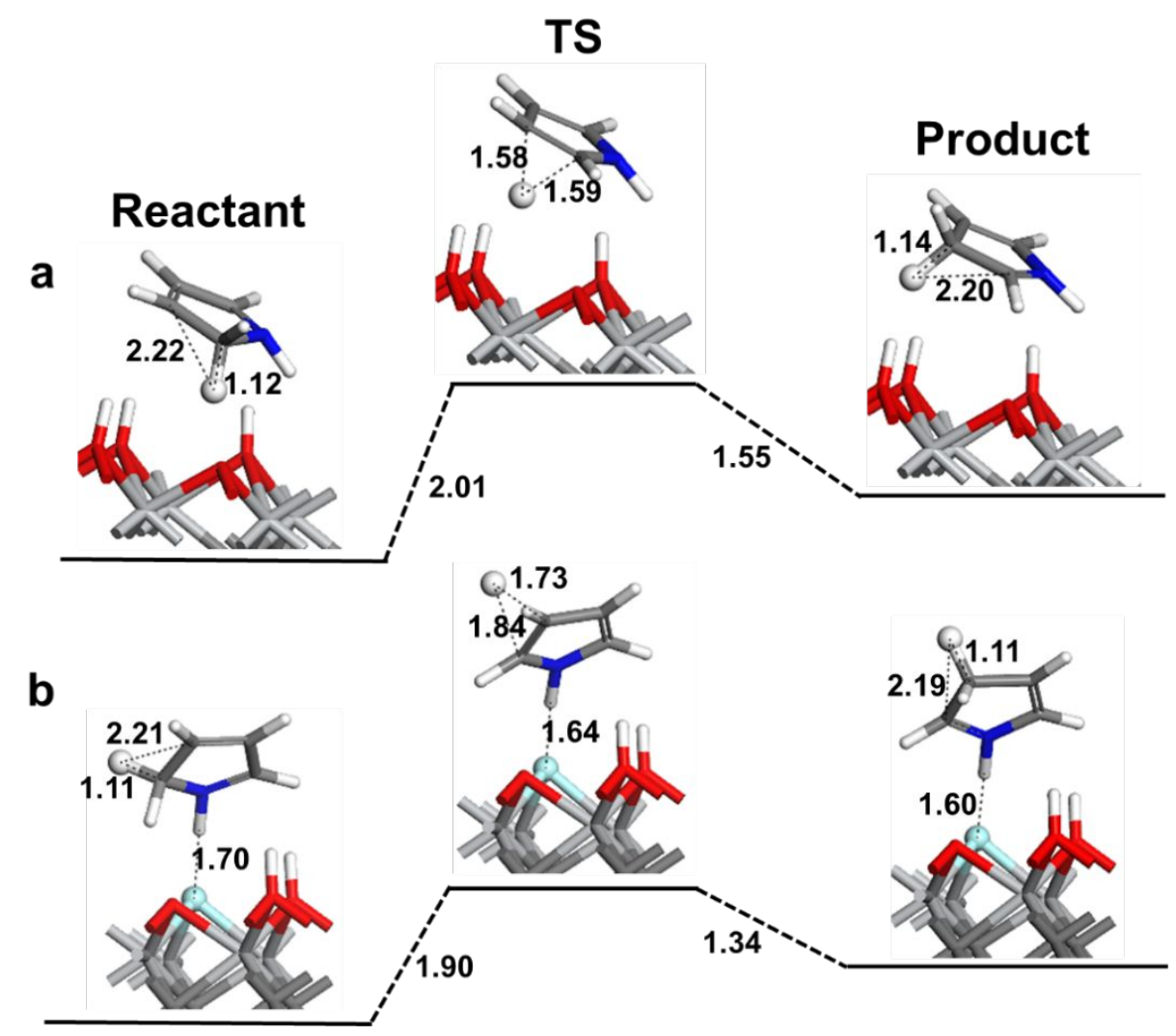

Figure S9. Reactant, transition-state, and product for a) $\alpha$ to $\beta$ proton transfer for pyrrole on MXene with $-\mathrm{O}$ terminated site, and $b) \alpha$ to $\beta$ proton transfer for pyrrole on MXene with $-\mathrm{F}$ terminated site. 


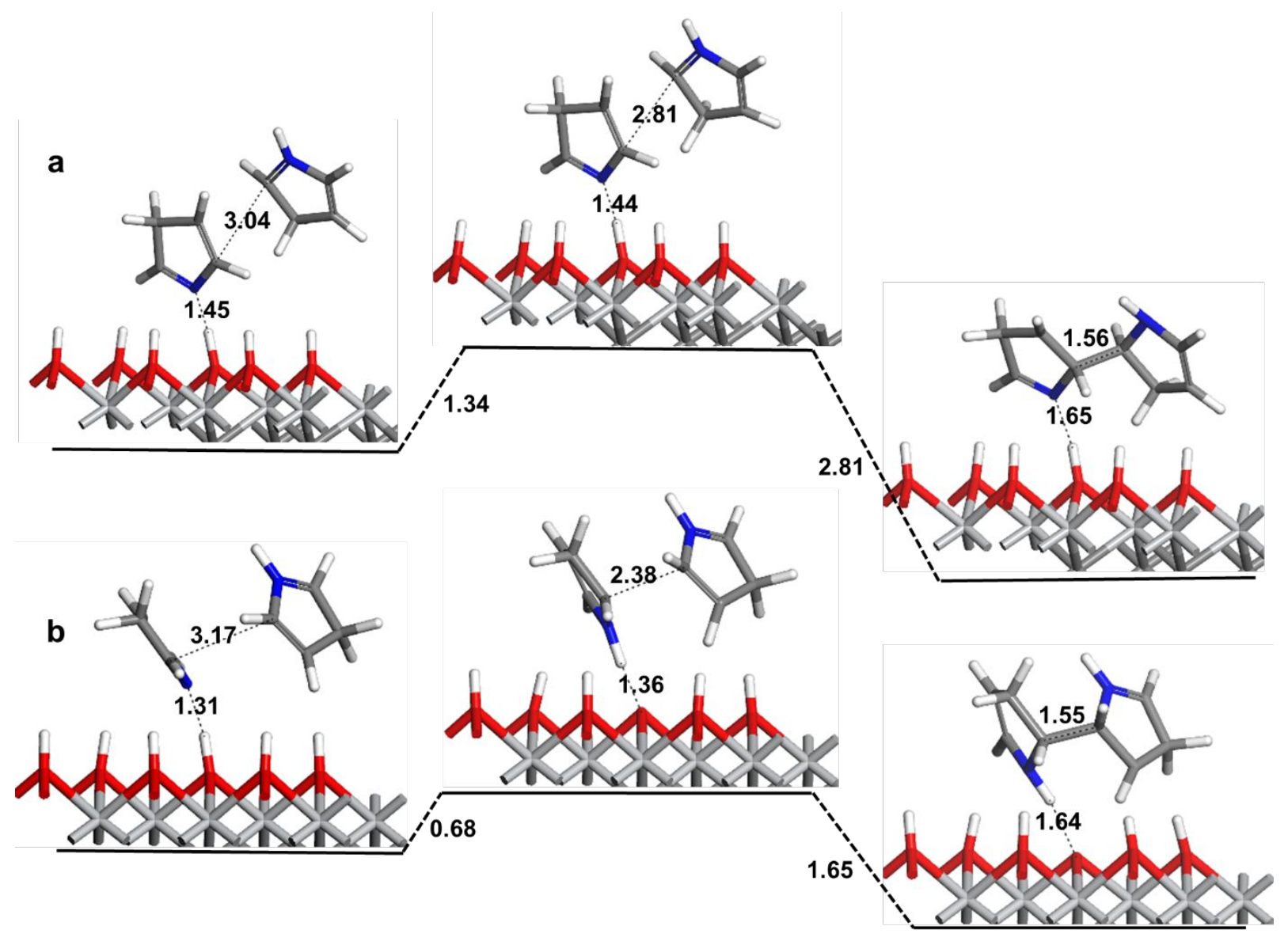

Figure S10. (a) Trans dimerization reaction mechanism of $\beta 1$-protonated pyrrole with $\beta 2$ protonated pyrrole on MXene with $-\mathrm{O}$ and $-\mathrm{OH}$ surface, (b) cis dimerization reaction mechanism of $\beta 1$-protonated pyrrole with $\beta 2$-protonated pyrrole on MXene with $-\mathrm{O}$ and $-\mathrm{OH}$ surface. 


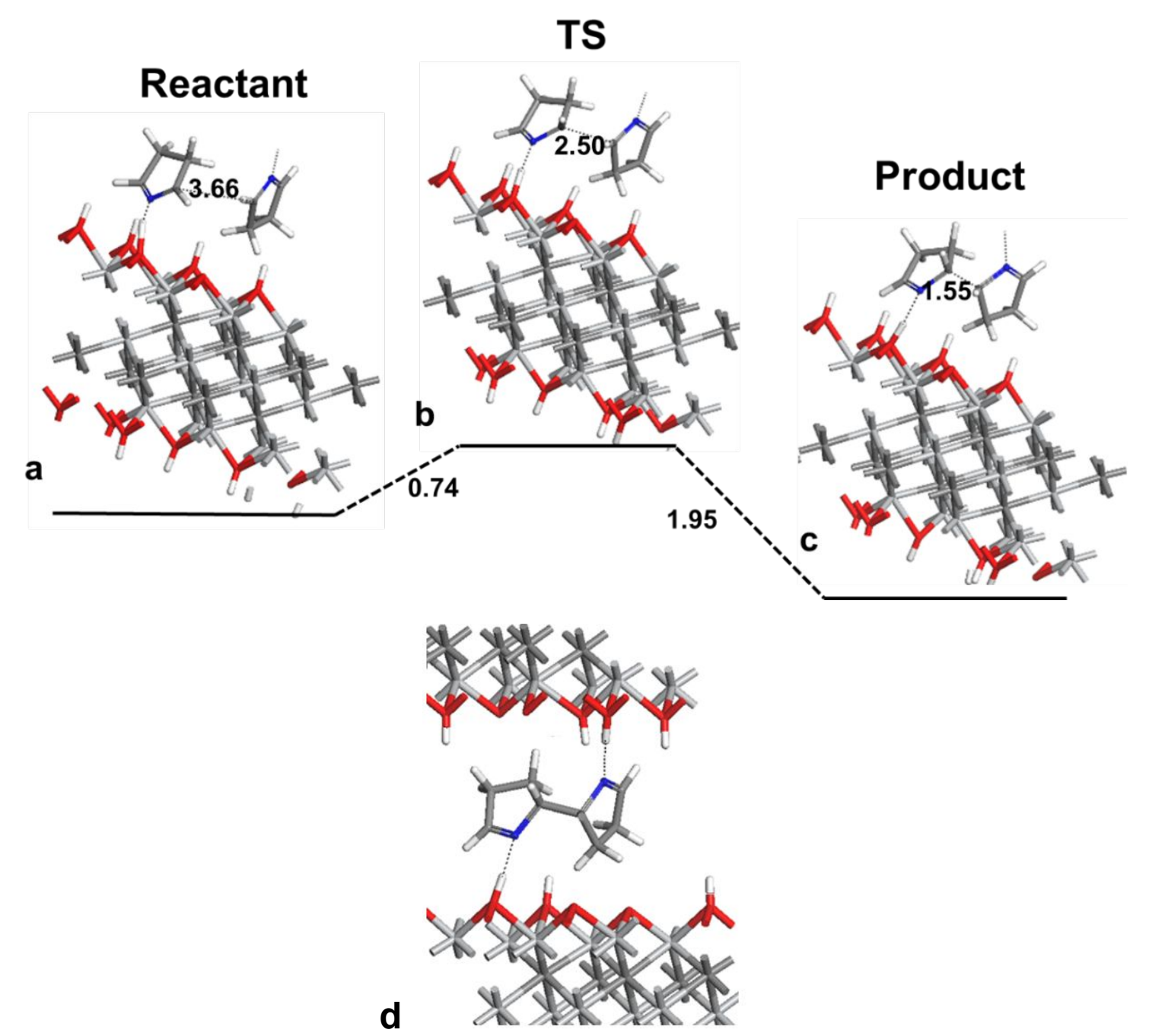

Figure S11. a) Reactant, b) transition-state, and c-d) product for dimerization of $\beta 1 \beta 2$ diprotonated pyrrole dimerization where both monomers are deprotonated from -NH group and coordinated by MXene surface via hydrogen bond interactions.

Another possible initialization-polymerization mechanism involves covalent bonding of $\beta$ protonated pyrrole monomer to the surface oxygens of MXene along with their $\alpha$-carbons, followed by polymerization from the other $\alpha$-carbon with a free pyrrole monomer. The reaction mechanism and energetics are given in Fig. S11. The activation barrier for $\beta$-protonated pyrrole bonding to MXene surface from $\alpha$-carbon is determined to be low $(0.15 \mathrm{eV})$. Although this activation barrier seems low, it is still higher than the activation barrier of pyrrole - $\mathrm{NH}$ deprotonation calculated (below $0.1 \mathrm{eV}$ ). Subsequent polymerization step with free pyrrole monomer has an activation barrier of $1.69 \mathrm{eV}$, which is higher than the polymerization barrier calculated for $\beta$-protonated pyrrole polymerization given in Table 3. Another possible mechanism involves the bonding of $\alpha$-protonated pyrrole monomer to the unsaturated surface oxygens from $\beta$-carbon, followed by polymerization from the other $\alpha$-carbon from with free 
pyrrole monomer; the initialization activation barrier is determined to be $0.50 \mathrm{eV}$ and polymerization from other $\alpha$-carbon is $1.61 \mathrm{eV}$, which is also higher than non-bonded polymerization mechanism based on proton transfers. This means that the in situ polypyrrole polymerization between $\mathrm{Ti}_{3} \mathrm{C}_{2} \mathrm{~T}_{x}$ MXene layers do not prefer to proceed with the covalent bonding mechanism.

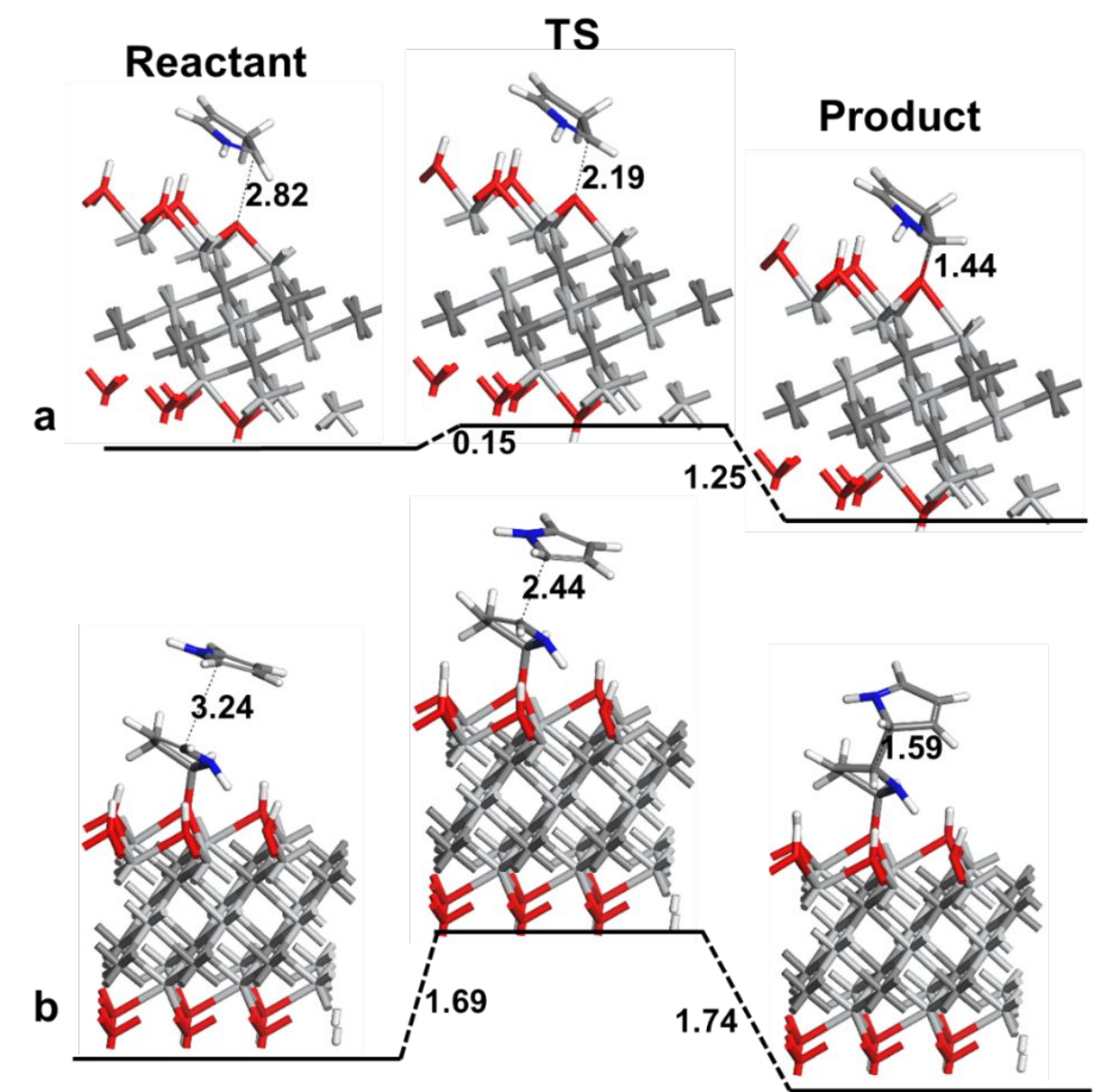

Figure S12. Reactant, transition-state, and product for a) $\beta$-protonated pyrrole bonding to MXene surface from $\alpha$-position, and $b$ ) dimerization of pyrrole with $\beta$-protonated pyrrole bonded to MXene surface. 

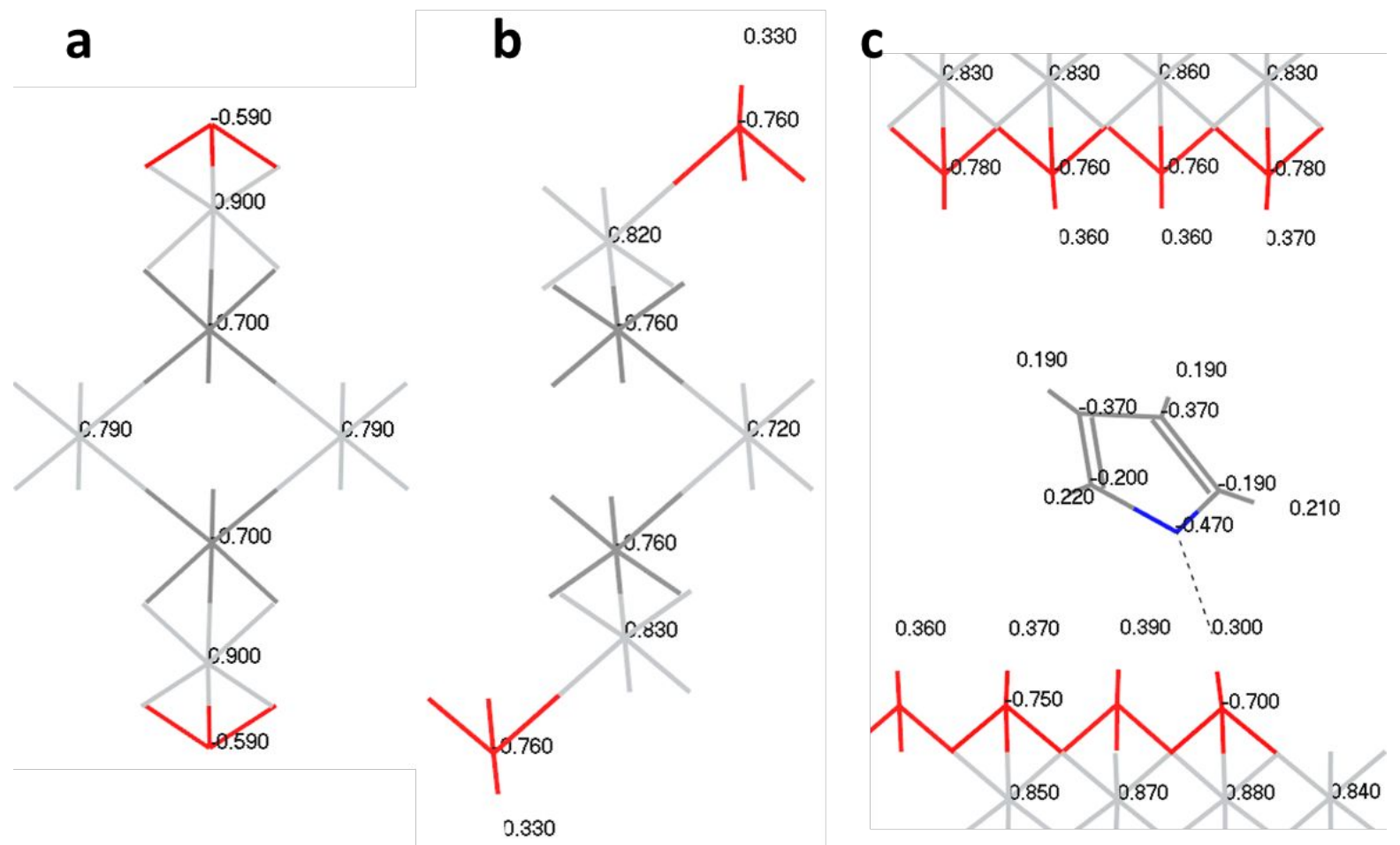

Figure S13. Mulliken atomic charges for a) -O terminated MXene, b) - OH terminated MXene, c) N-deprotonated pyrrole between MXene layers.

\section{Reactant}

a

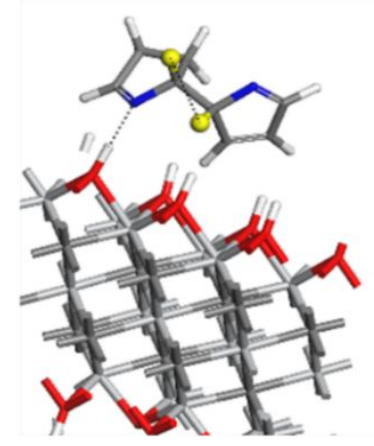

b
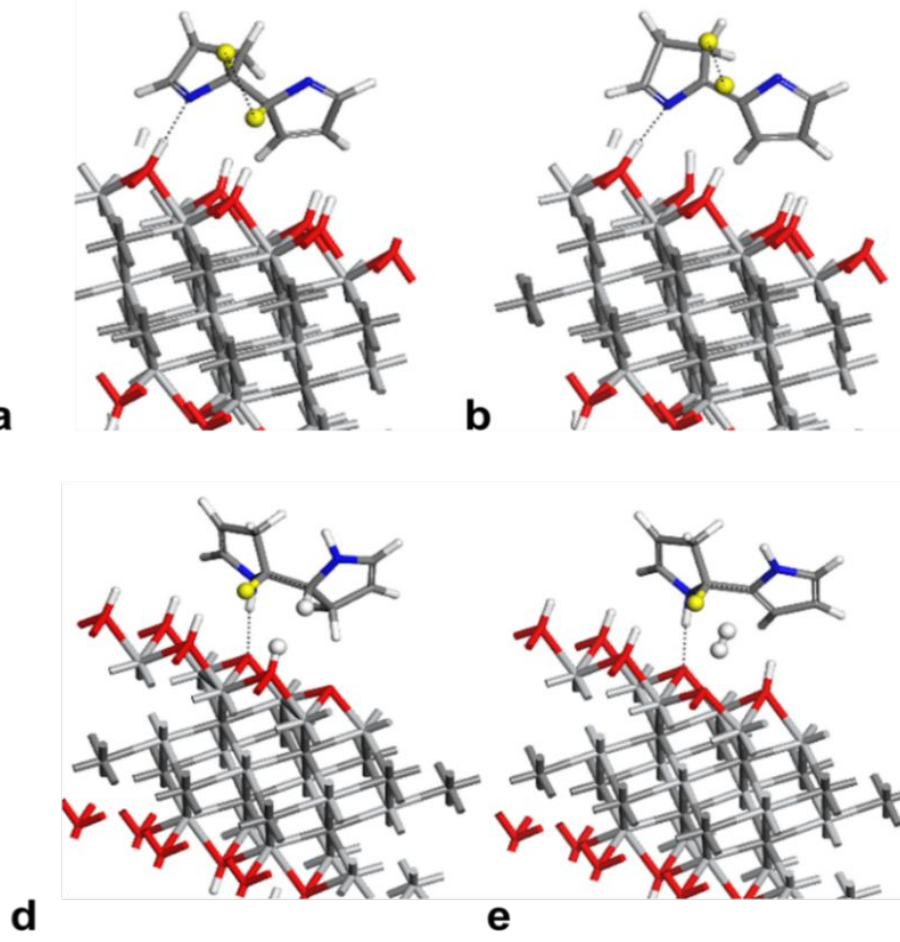

.

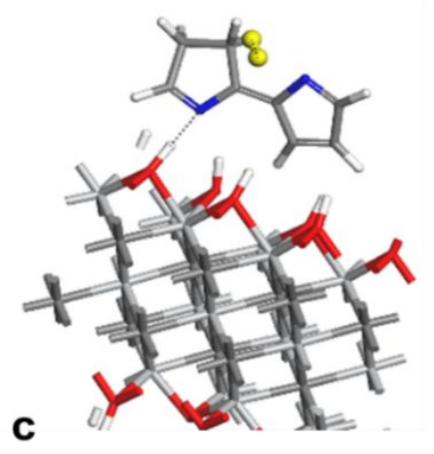

Product

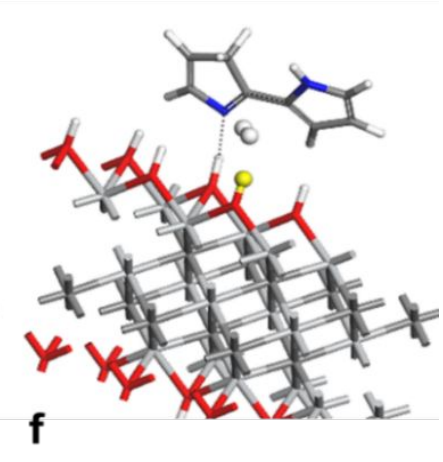

Figure S14. Deactivation mechanism for pyrrole dimer on Mxene surface by $\mathrm{H}_{2}$ gas formation. a) Reactant, b) transition-state, and c) product for $\mathrm{H}_{2}$ gas formation $\alpha$-carbon hydrogens. d) 
Reactant, e) transition-state, and f) product for $\mathrm{H}_{2}$ gas formation by surface hydrogen and hydrogen bonded to $\alpha$-carbon.

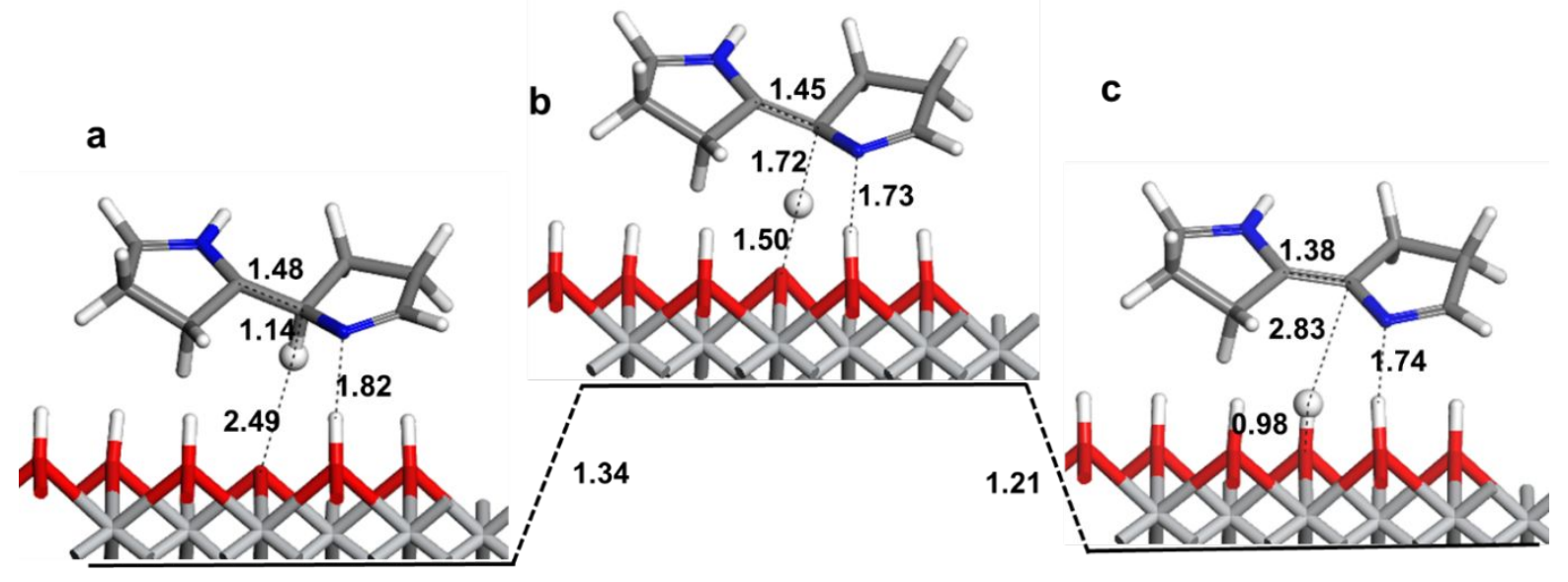

Figure S15. The deactivation of one pyrrole in dimer via transfer of bonded $\alpha$-carbon hydrogen directly to the MXene surface in trans conformation.

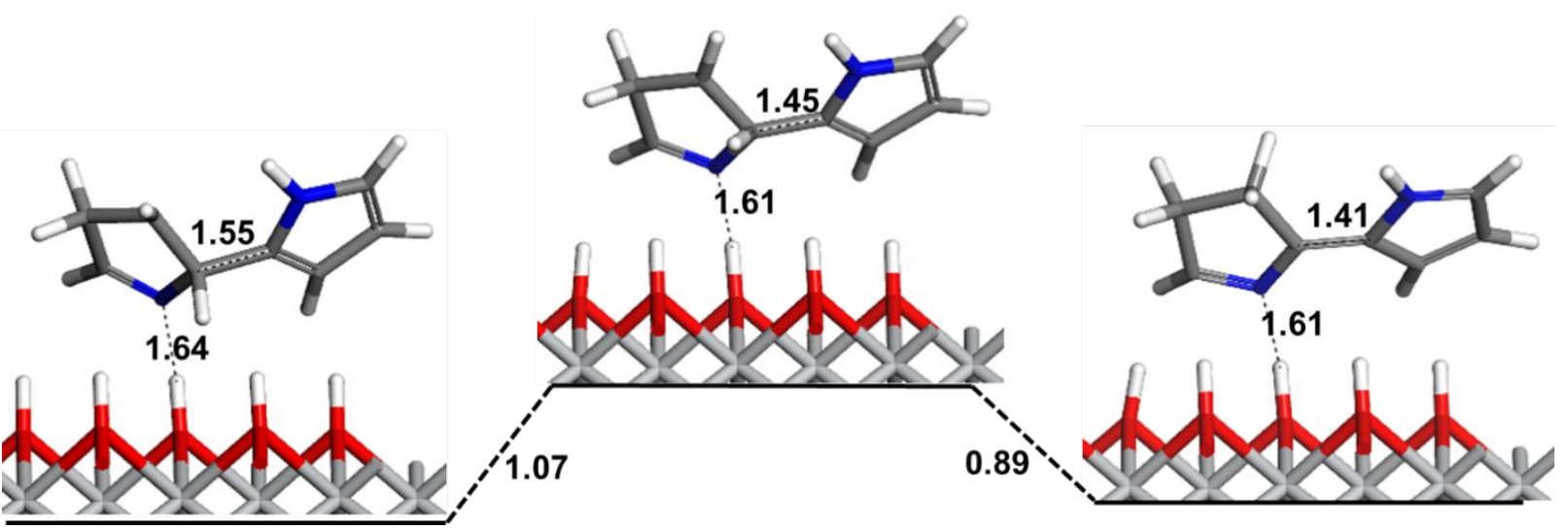

Figure S16. The deactivation of one pyrrole in dimer via transfer of $\alpha$-carbon hydrogen to $\beta$ carbon

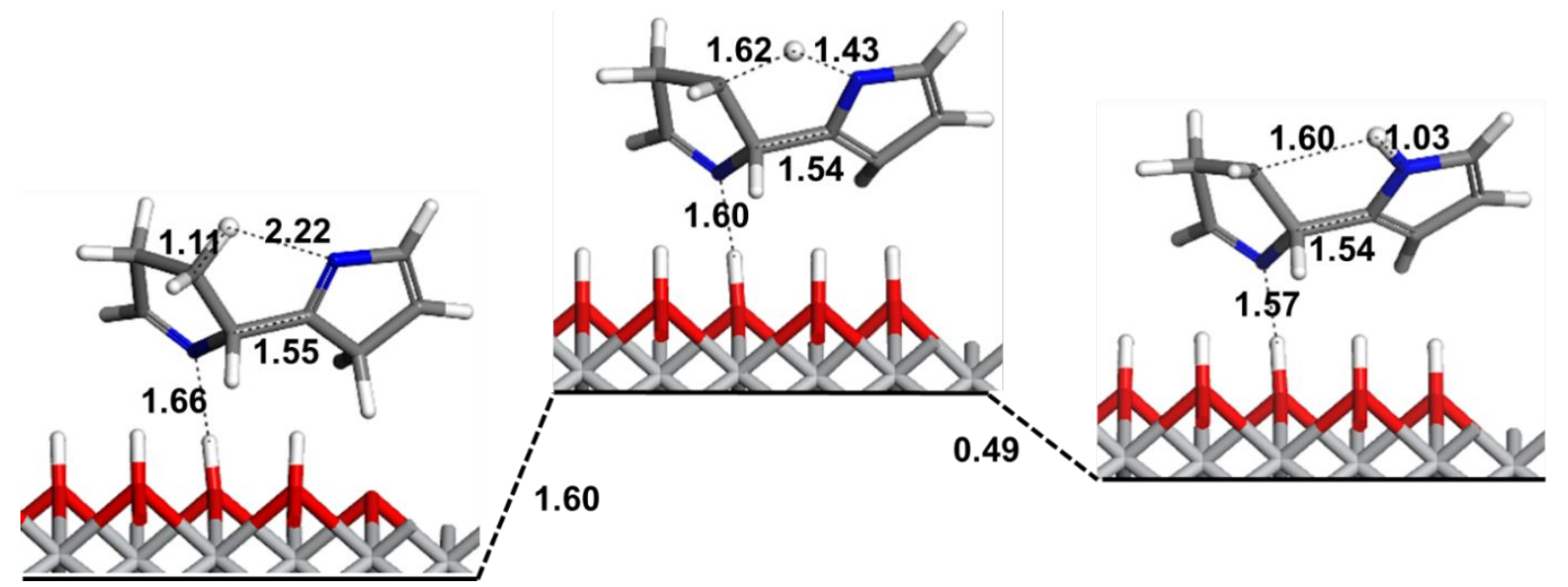

Figure S17. The deactivation of dimer via transfer of $\beta$-carbon hydrogen of monomer 1 to the deprotonated nitrogen atom of monomer2. 
a
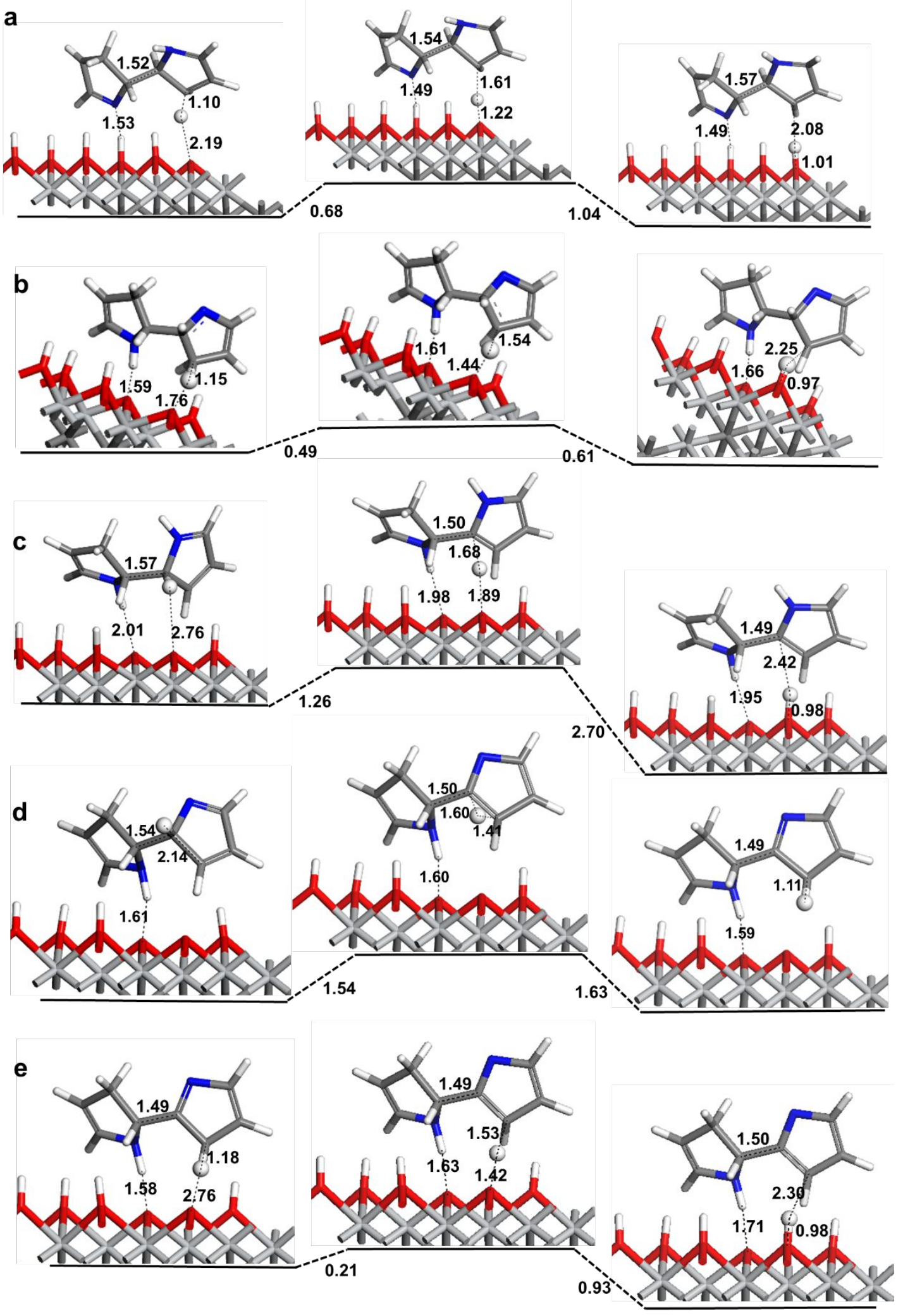

Figure S18. The deactivation of one pyrrole in dimer formed by reaction of two $\beta 1$-protonated pyrrole via transfer of $\beta$-carbon hydrogen to the MXene surface for a) trans and b) cis dimers; c) transfer of bonded $\alpha$-carbon hydrogen directly to the MXene surface in cis dimer; d) transfer of proton from $\alpha$ to $\beta$-carbon followed by e) transfer of this $\beta$-carbon hydrogen to the MXene surface in cis dimer. 

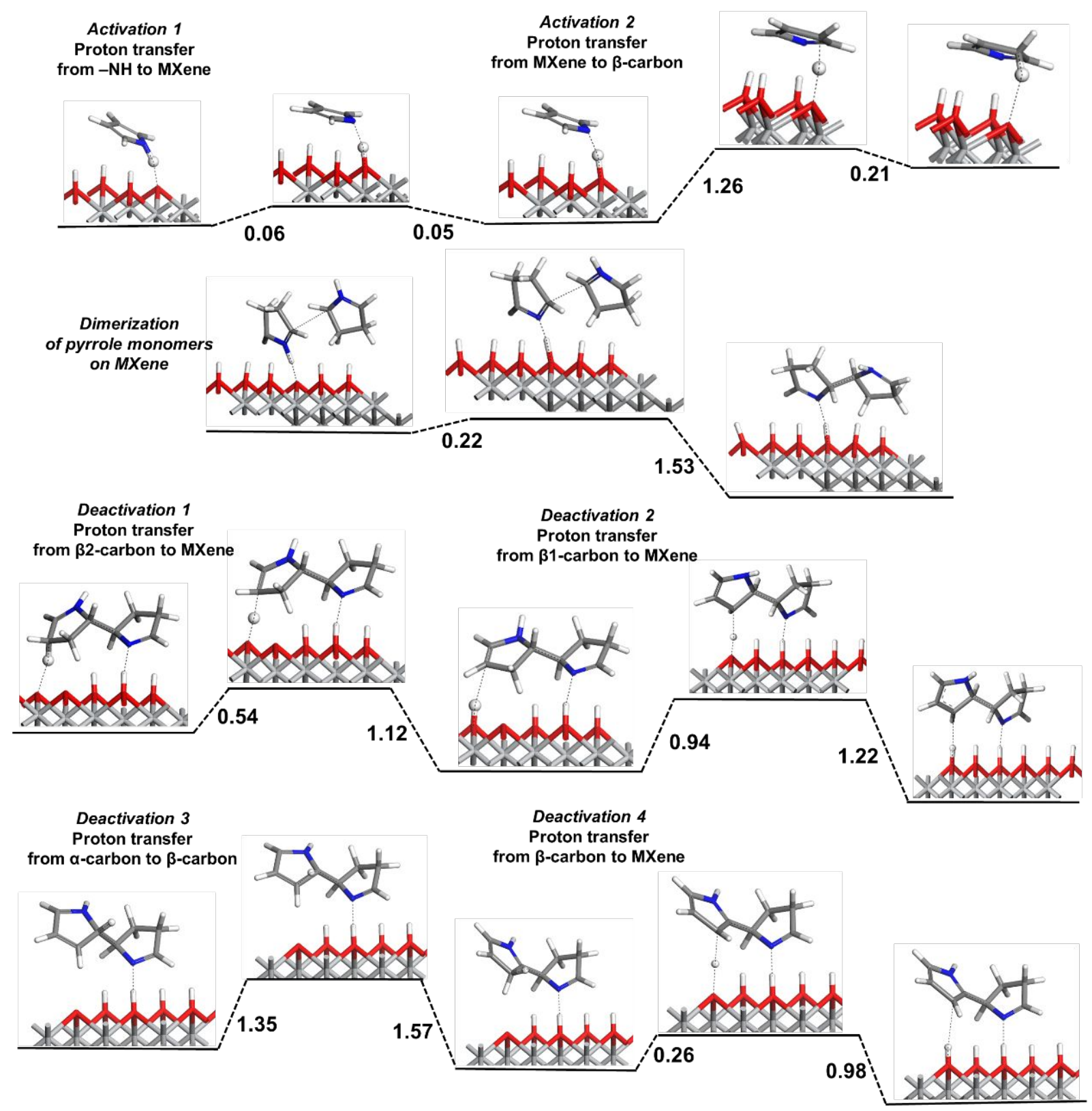

Figure S19. Calculated mechanisms for the trans polymerization of $\beta 1 \beta 2$ biprotonated pyrrole monomers. Protonation of second $\beta$-carbon and deactivation of second pyrrole are not shown in the mechanism. 